\title{
O CAIXEIRO-VIAJANTE REVISITADO: OS PARADOXOS DA “FÚRIA NARCÍSICA" NA LITERATURA E NO CINEMA
}

\author{
THE SALESMAN REVISITED: THE PARADOXES OF THE \\ "NARCISSISTIC RAGE" IN LITERATURE AND CINEMA
}

\author{
Rodrigo Vieira MARQUES ${ }^{1}$
}

\begin{abstract}
Resumo: O presente artigo busca estabelecer uma relação entre o filme $O$ Apartamento, de Asghar Farhadi, e a peça de Arthur Miller, A morte de um caixeiro-viajante. Tendo por fundamento a noção psicanalítica de narcisismo e a teoria do "modo de endereçamento", busca-se desenvolver uma discussão em torno da noção de "fúria narcísica" (Kohut) e o que se considera ser seus paradoxos. Destaca-se, principalmente, dois paradoxos que se encontram entrelaçados: em primeiro lugar, o modo como, nessa condição psíquica, o inimigo é uma parte não reconhecida do próprio Self e, em segundo lugar, o modo como o outro, que serve de tela para projeção de sentimentos de hostilidade, torna-se um presente-ausente, não percebido em sua inteireza. Nesse contexto, a "fúria narcísica" origina-se, sobretudo, da ausência de um registro psíquico integrado da alteridade e, por conseguinte, de suas complexidades e ambivalências. A partir dessas questões, espera-se mostrar como tanto no filme como na peça teatral que lhe serve de intertexto um "narcisismo extremamente vulnerável" e suas falhas vão sendo elucidados.
\end{abstract}

Palavras-chave: Literatura, Psicanálise e Cinema. Fúria narcísica. Narcisismo. Heinz Kohut.

Abstract: This article seeks to establish a relationship between Asghar Farhadi's film, The Salesman, and Arthur Miller's play, Death of a Salesman. Based on the psychoanalytic notion of narcissism and the theory of "mode of address", we seek to develop a discussion around the notion of "narcissistic rage" (Kohut) and its paradoxes. Two intertwined paradoxes mainly stand out: first, the way in which, in this psychic condition, the enemy is an unrecognized part of the Self itself and, secondly, the way in which the other, which serves as a projection screen for feelings of hostility, becomes a present-absent, not perceived in its entirety. In this context, the "narcissistic rage" originates, above all, from the absence of an integrated psychic register of the otherness and, consequently, of its complexities and ambivalences. Following these questions, we hope to show how in both film and play, which serves as an intertext, an "extremely vulnerable narcissism" and its failures get to become elucidated.

Keywords: Literature, Psychoanalysis and Cinema. Narcissistic rage. Narcissism. Heinz Kohut.

\section{Cinema e literatura, Oriente e Ocidente: questões de endereçamento}

Entre o filme $O$ Apartamento, de Asghar Farhadi, e a peça A morte de um caixeiroviajante, escrita por Arthur Miller, podemos encontrar um profícuo diálogo intertextual. Dentre outros temas, essa peça reflete uma contundente crítica ao "sonho americano" de uma vida repleta de sucesso e de felicidade. Essa observação inicial poderia conduzir a nossa leitura do filme a alguns caminhos diferentes e, aparentemente, excludentes. O filme seria, por

\footnotetext{
${ }^{1}$ Doutor em Filosofia pela Universidade Federal de São Carlos e pós-doutor em Literatura pela Universidade Estadual Paulista Júlio de Mesquita Filho. Professor da Faculdade de Letras da Universidade Federal de Goiás. Psicanalista em formação (GEPG/IPA). rodriggus@ gmail.com
} 
um lado, uma crítica desconstrucionista, abarcando discursos culturais e religiosos, das consequências desastrosas do que, até então, predominantemente servia de fundamento ideológico ao imaginário ocidental, especialmente a política americana, cujo ápice podemos encontrar na tragédia monumental da derrubada das Torres Gêmeas do World Trade Center em Nova York. Por outro lado, trilhando os caminhos da experiência estética, a narrativa, apresentada por Farhadi, poderia ser, simplesmente, um diálogo intertextual no qual se buscaria, na cultura iraniana, reviver o drama humano evidenciado na peça de Arthur Miller. Enquanto, em um caminho, seriam predominantes as questões políticas, no outro, predominaria a experiência estética. Que caminho seguir?

Considerando os estudos contemporâneos, particularmente aqueles desenvolvidos pela teoria do cinema, sabemos que nem sempre, quando estamos diante de questões dessa natureza, a solução de um possível impasse se dá na escolha de um único caminho. Não que seja possível trilhar, plenamente, todos os caminhos ao mesmo tempo, nem mesmo que a solução seja a de se contentar em escolher apenas um, mas de se fazer a experiência de um espaço que, muitas vezes, permanece olvidado: o intervalo entre os caminhos, o entrelugar entre os lugares, não só a relação entre os diferentes pontos de vista, mas também de suas consequências teóricas. A nosso ver, a relação entre o filme e o espectador pode servir como a encruzilhada de todos esses vértices. Nesse sentido, partindo-se do pressuposto de que o filme nos apresenta diferentes pontos de vista, como seria pensar o entrecruzamento desses caminhos enunciados, quando o que está em questão é a relação entre o filme e o espectador? Como pensar esse entrelugar? A esse respeito, é pertinente nos lembrarmos da pergunta formulada por Ellsworth (2001) ao procurar refletir sobre esse entrelugar, especialmente tendo por referência a teoria do modo de endereçamento (mode of address): "o que o filme pensa que eu sou?"

Ao se perguntar o que um determinado filme "pensa" de seus espectadores, o que se procura investigar, além dos laços existentes entre o texto de um filme e a experiência do espectador, é a relação entre indivíduo e sociedade, entre cultura e psique. Ao mesmo tempo, é aquilo que se encontra presente no texto fílmico, mas não deixa de interagir e de afetar diretamente os destinatários reais e/ou imaginários de seu discurso. $\mathrm{O}$ endereçamento, por conseguinte, como nos aponta Ellsworth (2001) ao longo de seu texto, torna-se um acontecimento psicossocial. Falar em evento, em acontecimento, significa, pois, dizer que o endereçamento não se encontra mais preso à estrutura do texto, haja vista que, entrando em 
cena o espectador, o seu imaginário e os seus desejos, novos horizontes e abordagens teóricas são possíveis, dentre elas, o saber psicanalítico.

A psicanálise surge, pois, especialmente neste artigo, como um caminho de articulação dos diferentes aspectos da experiência que o espectador faz do cinema, ou, caso se prefira, como um dos diferentes aspectos que compõem essa relação. Nesse sentido, a escolha por uma ou outra compreensão do lugar da psicanálise nesse diálogo será simplesmente tributária do posicionamento teórico do leitor. O que se acredita permanecer como consenso é a possibilidade de o discurso psicanalítico contribuir com a compreensão que um espectador pode ter da relação que ele propriamente constrói com um determinado filme. É a relação entre cinema e psicanálise que emerge em nosso discurso. Não se tratará, contudo, de uma "psicanálise aplicada", ao menos conforme a sua compreensão clássica. Afirmar isso significa que não é nossa pretensão uma análise do filme tal como aquela que se estabelece em uma sessão psicanalítica. Nada de tratar o personagem como um analisando falando de suas angústias, sonhos e fantasias. Em outros termos, não é nossa pretensão colocar o filme, seus personagens e equipe técnica no divã, o que, deveras, não faria sentido. O que se espera então?

Uma experiência psicanalítica, quando se pensa também em um processo psicoterapêutico intermediado pela fala, ocorre no encontro dialógico entre duas subjetividades, é sempre um caminho de construção e reconstrução de sentidos de uma via dupla, situada no "aqui e agora" da sessão, em um instante que se dá como acontecimento único. Quando pensamos na leitura de um filme, não estamos diante de uma determinada subjetividade que, com uma historicidade e idioma únicos, deseja se conhecer ao se revelar a um outro com o qual estabeleceu um vínculo afetivo. Esse outro é por ela escolhido como um interlocutor confiável por apresentar uma escuta suficientemente acolhedora, e isso independentemente das vicissitudes desse processo. Pelo contrário, na leitura de um filme, estamos na "lida" com um texto no qual é possível vislumbrar "traços" de subjetividade, muitas vezes, reflexos de nosso próprio olhar.

A leitura do filme se dá, nessa perspectiva, como o relato do que a sua narrativa mobiliza em cada um de nós e o que essa experiência nos leva a pensar. Daí não fazer sentido a ressalva de que tal leitura não é condizente por não se equiparar às intenções de quem quer que assuma, em relação ao filme, um papel de autoria. As intenções do diretor não constituem 
o foco de nossa leitura, haja vista partirmos da compreensão do filme como uma instituição cultural aberta, logo, o foco de nossa leitura ser propriamente a experiência fílmica ${ }^{2}$.

Não desconsiderando, todavia, o pressuposto de que um filme é, sobretudo, feito para alguém, seja ele real e/ou imaginário, cabe-nos também a constatação de que uma narrativa cinematográfica terá sempre, por referência, uma determinada "posição de sujeito", ou seja, uma configuração de relações de poder e de sentido. Para que um filme faça sentido, é preciso que, mesmo que fantasiosamente, o espectador se veja na posição que lhe é apresentada. Com efeito, há um “(...) invisível processo que parece 'convocar’ o espectador a uma posição a partir da qual ele deve ler o filme” (ELLSWORTH, 2001, p. 17). Por conseguinte, “(...) o espectador deve ser capaz de adotar - nem que seja apenas imaginária e temporariamente - os interesses sociais, políticos e econômicos que são as condições para o conhecimento que eles constroem" (ELLSWORTH, 2001, p. 18). Uma vez que, ao longo de um filme, podemos assumir diferentes pontos de vista ou que os diferentes componentes narrativos e discursivos do filme são capazes de mobilizar diferentes aspectos de nossa subjetividade - muitas vezes, inclusive, contribuindo para processos de subjetivação -, é possível constatar que temos o poder de reescrever os diferentes endereçamentos construídos, consciente ou inconscientemente, por um determinado diretor e sua equipe. O que isso quer dizer?

Mesmo que um filme seja sempre feito pensado em um espectador ou espectadores em particular, na perspectiva do modo de endereçamento que adotamos, torna-se secundária, paradoxalmente, a indagação se o filme $O$ Apartamento, por exemplo, fora feito para iranianos ou para americanos, orientais ou ocidentais. A intenção do diretor de um filme, diante da experiência de cada espectador, acaba se diluindo e dando espaço ao volátil entrelugar das relações humanas. É certo que nem sempre somos o que o filme pensa que nós somos, ou seja, nem sempre o filme acerta aquilo que poderia produzir em seus espectadores um efeito de identificação, dado que a experiência de um filme e a relação espectadornarrativa convoca também, no próprio espectador, as diferentes e ambivalentes partes que constituem a sua subjetividade. Sendo assim, a "posição de sujeito" à qual um filme parece nos convocar, por sua vez, não deixa de ser reconstruída pela resposta que o espectador dará ao tecer, em sua experiência, os fios de sentido da narrativa.

Um filme se constitui por diferentes modos de endereçamento, e, ao ver um filme, independentemente de nosso gênero, raça e cultura, assumimos um processo de negociação de

\footnotetext{
${ }^{2}$ Essa compreensão, sem dúvida, não seria possível sem as contribuições dadas - em especial, na literatura pela leitura das obras de R. Barthes, U. Eco, H. R. Jauss e W. Iser.
} 
sentidos, nem que seja com aquela parte de nós mesmos que, ao não ser negada, ou antes, ao ser reconhecida e legitimada, permite-nos reviver, ao nos projetarmos também nos componentes constitutivos da trama cinematográfica, os nossos "culposos e ambivalentes prazeres”. Mas, como já assinalara Ellsworth (2001), todo esse processo é invisível, haja vista que, como podemos identificar na busca de seus traços, a experiência de se ver um filme é, principalmente, relacional, uma relação que se constrói no intervalo entre identidade e diferença. Nessa perspectiva, o que a leitura do filme $O$ Apartamento poderia suscitar em um psicanalista ou mesmo em um espectador familiarizado em reconhecer as manifestações de aspectos inconscientes de nossa vivência do mundo?

Para um psicanalista, ao menos em uma primeira leitura, caso paute sua clínica por um viés mais freudiano, o filme poderia versar sobre uma mulher que é agredida, "talvez" violentada. O “talvez" se justificaria porque, quanto à violação, não há uma indicação precisa no filme, nenhuma cena ou referência explícita, nenhuma comprovação. Quanto a isso, vale ressaltar que, mesmo tendo sido hipoteticamente a violação uma fantasia delirante e uma construção da ordem do discurso, a importância de seu poder traumático tampouco seria menor. Sabe-se que, pelo que tudo indica, houve um ato de violência, parecendo ser esse o tema principal da narrativa. No entanto, mesmo esse fato, que poderia trazer à tona todo um arsenal teórico freudiano sobre trauma e sexualidade, parece nos apresentar diversas possibilidades de leitura, dado que nos encontramos, inegavelmente, no terreno de uma cultura diferente da nossa.

Ora, essa diferença, ao se propor uma reflexão pautada pelo discurso psicanalítico, não nos deixa esquecer também de que a própria psicanálise é um artefato institucional de uma cultura em particular. Isso valeria, inclusive, mesmo se essa cultura conseguisse demonstrar que o que ela vê nas demais é tal como ela vê e não como estas veem a si mesmas - por exemplo, a "comprovação" de uma universalidade do Complexo de Édipo -, o que nos lança no terreno da pura tautologia e nos faz remontar às complexas discussões sobre a traduzibilidade ou intraduzibilidade de nossa experiência. Isso não desqualifica o saber psicanalítico como um construto social significativo e eficaz, apenas reconhece as suas raízes históricas e sociais. Além disso, há muito já sabemos que a experiência do verdadeiro não habita apenas o laboratório, nem muito menos carece de uma universalidade matemática. Levando em conta essas considerações, que outros sentidos o saber psicanalítico pode nos ajudar a construir a partir da vivência desse filme? 
Mesmo reconhecendo a importância dos efeitos de intertextualidade na análise desse filme, somos levados por Farhadi, indiscutivelmente, ao frontispício do Outro e de suas territorialidades. A experiência da diferença, propiciada por esse encontro, curiosamente mobiliza e revela nossas angústias, reflete aspectos desconhecidos de nós mesmos, embora seja capaz de gerar paradoxalmente processos de identificação. Partindo desse pressuposto, que subjetividade ou subjetividades podemos encontrar nas tramas narrativas do filme $O$ Apartamento?

A esse respeito, vale salientar que subjetividade ou sujeito é um nome dado à experiência que o homo sapiens faz de si mesmo e do mundo. Em uma perspectiva que nos é mais contemporânea, esse ser que, na modernidade clássica, passara a se nomear sujeito, descobriu-se ser uma invenção. Humanidade e subjetividade são invenções porque não nascemos humanos, tornamo-nos humanos - conceito, por sua vez, volátil tanto social como historicamente - e, por consequência, encontramo-nos, de modo intermitente, em diferentes processos de subjetivação (SILVA, 2001). Humanidade, logo, não é algo que nos é intrínseco tão somente por pertencermos à espécie humana, mas sempre um construto. Houve uma época em que acreditávamos ser o centro do universo, um todo coeso e indivisível. Hoje já se acredita que estamos longe de sermos totalmente senhores de nós mesmos, pois começamos a nos compreender, em razão dos diferentes movimentos históricos de nossas ideias, como um "efeito da diferença". Assim, não apenas somos um ser que fala, mas que é falado, como poderiam destacar, por exemplo, os desdobramentos da linguística saussuriana. Por conseguinte, do entrecruzamento dos diferentes vértices e discursividades que acabamos de apenas insinuar e que estão presentes arqueologicamente em nosso discurso hodierno, podemos deduzir que somos construídos por nossas experiências, inclusive, pela "violência simbólica" de nossas contingências, seja na relação entre psique e cultura, seja na relação indivíduo e sociedade.

Pensando nessa violência, seria possível ver no filme de Farhadi, como já cogitamos anteriormente, o modo como se dá a gênese de uma experiência traumática? O modo como um corpo estranho violentamente e sem possibilidade de representação, de simbolização, invade o nosso psiquismo? É aqui que a nervura entre os diferentes olhares de um diretor de cinema iraniano e de um escritor americano nos leva a pensar, além do diálogo entre Oriente e Ocidente, também nas relações entre literatura e cinema. Nessa perspectiva, em nossa compreensão, os personagens e cenários do texto literário se tornam quase que sombras do texto fílmico, como se o filme se tornasse um duplo, mutatis mutandis, muito verossímil da 
peça teatral e, assim, tal como na fotografia analógica, quase que o seu negativo. Tomando essa hipótese como ponto de partida, conforme veremos, o que encontramos vai além de uma experiência traumática restrita a uma "violência sexual", pois remete-nos a uma dialética que mobiliza, antes do drama edípico, a nossa percepção de uma trama mais primitiva.

\section{Emad e Biff: a experiência do duplo na dialética entre figura e fundo}

Rana encontrava-se sozinha em seu apartamento. Após ouvir o toque do interfone, abre a porta de sua casa acreditando tratar-se do marido. Após essa sequência, o que vemos é a indicação de que não poderia ser o seu marido Emad, já que ele ainda estava no mercado, fazendo as compras que ela havia pedido. Isso se confirma quando, chegando em casa, ele se depara com marcas de sangue nas escadas e a notícia de que a sua mulher estava hospitalizada. O que aconteceu? Um estranho entrou em sua casa, talvez um dos clientes da antiga mulher que morava no apartamento, "uma mulher leviana", dirão os vizinhos. Rana parece ter sido confundida com uma "prostituta". Mas Rana foi violentada? Não teria sido, como já indicamos, o "terrível susto" fruto de um infeliz mal-entendido? Essa dúvida parece martelar ainda mais, em nossa mente, quando encontramos o possível agressor: um velho cardíaco e muito frágil. Não seria, pois, o caso de não tirarmos conclusões precipitadas sobre o que teria acontecido com Rana tal como Freud não conseguia mais acreditar em sua neurótica? Ao dizer isso em uma carta endereçada a Fliess, em 21 de setembro de 1897 (FREUD, 1986, p. 265-267), o que se vislumbrava era a passagem do método catártico para a busca de uma etiologia simbólica das neuroses, as bases de um saber metapsicológico, a descoberta do papel da fantasia na formação de nossa subjetividade, a descoberta de uma organização pulsional. Mas se não pensamos o filme a partir da encenação da gênese de uma possível neurose traumática, ao menos no sentido clássico, de que outro modo poderíamos compreendê-lo?

Tentando responder a essa questão, é importante lembrarmo-nos da constatação de Merleau-Ponty (1996) da importância da Psicologia da Forma ou Teoria da Gestalt ao pensarmos a nossa experiência do cinema. Lembremo-nos de que, com essa teoria, aprendemos que o nosso modo de perceber o mundo se dá mediado por relações de figura e fundo. O que vemos é uma estrutura, uma Gestalt, que se destaca de um fundo. O interessante dessa compreensão, porém, é que vamos nos acostumando com determinadas figuras, sem nos darmos conta ou nos perguntarmos sobre o que acontece quando passamos a ver por figura aquilo que é fundo e por fundo aquilo que é figura. No filme de Farhadi, Emad e Rana são 
atores que se preparam para a encenação de uma peça de Arthur Miller, intitulada A morte de um caixeiro-viajante. Essa peça aparece como um dos elementos do fundo que sustenta o drama que vemos se passar em Teerã. Podemos nos perguntar: e se deslocássemos a nossa atenção para a peça e deixássemos, mesmo que por um breve momento, Emad e Rana como elementos do fundo, o que encontraríamos?

Em primeiro lugar, a hipótese de que $O$ Apartamento talvez seja a encenação do drama de um sujeito ausente, portanto, aparentemente tácito, embora fundamental para a narrativa. $\mathrm{O}$ seu personagem principal, o caixeiro-viajante, é um ausente presente que faz com que Emad e Rana se tornem, em nossa imaginação, os personagens encenados por Willy e Linda, o casal principal da peça de Arthur Miller. Quando o fundo se torna figura, o velho se torna o personagem principal do filme. Não é, em vão, que, traduzindo para o português, tanto no título original como em inglês, o filme se chama $O$ vendedor, em francês $O$ cliente e em espanhol $O$ viajante. O que acontece quando fazemos essa inversão entre os personagens do filme e da peça? Para tanto, precisamos compreender um pouco melhor sobre o que versa $A$ morte de um caixeiro viajante.

Esse texto de Arthur Miller pode ser visto como um retrato magistral do sonho americano, ou antes, de seu fracasso, de seu pesadelo. Um velho de 60 anos, Willy, que trabalhava por volta de 35 anos como caixeiro-viajante se vê chegando à velhice sem a ascensão social que tanto desejava. Não tinha mais condições físicas e emocionais para manter o seu ritmo de trabalho. Sua esposa, por sua vez, retratava bem a mulher submissa e fiel aos desejos de seu marido. O conflito se dá na relação do casal entre si e com os filhos Happy e Biff, o que coincide com a volta desse último para casa. O que se sabe é que as relações entre Willy e Biff nunca foram muito fáceis. Primeiro, era uma relação "perfeita", carregada de muito amor. No entanto, algo acontece e muda tudo, o que o leitor ficará sabendo quase no final da narrativa.

Willy era um homem sonhador, cheio de ideias de grandeza. Demitido, vendo seus projetos fracassarem, seus filhos não correspondendo à genialidade que tanto neles procurava enxergar, o que lhe restava era uma sobrevida fronteiriça entre realidade, fantasia e delírio. Seu irmão Ben, já falecido, era o interlocutor imaginário com quem compartilhava seus fracassos e arroubos megalomaníacos. Em outros termos, Willy era um homem ressentido, rodeado por objetos idealizados, por uma culpa ora consciente, ora inconsciente, habitado por fantasmas. Não tolerando o fracasso, ele passou a viver em um mundo onírico. Constantemente conversava sozinho com suas lembranças, em voz alta, em lugares públicos, 
em uma mescla de passado e de presente. Como se não tivesse um aparelho mental capaz de conter suas angústias (BION, 1994), ele vivia "vomitando" tudo o que lhe vinha à mente. Mas voltemos à relação entre Willy e Biff, uma das chaves da peça e cuja gênese está expressa em uma das cenas representadas por Emad e Rana no filme, a cena do banheiro. O que Biff teria contra Willy? Qual a razão de tanto ódio? Biff tinha a possibilidade de ser aceito por uma grande universidade e se tornar um grande jogador. No entanto, não conseguiu passar em uma disciplina na escola. Precisava de nota. Temia muito decepcionar o pai que tanto admirava e idealizava. Como o pai estava viajando, ele resolveu ir ao seu encontro e, assim, explicar o que estava acontecendo e pedir a sua ajuda. Contudo, chegando lá, encontra o pai com uma amante. De idealizado, o pai passa a ser uma fraude, uma mentira, uma farsa. Desde então, Biff abandona os estudos, ficando de tempos em tempos longe da família. A relação entre pai e filho nunca mais será a mesma, passando a ser dominada pelo ódio.

Ao saber, porém, das tentativas do pai em se matar, Biff começa a rever seus conceitos. Tenta encontrar um emprego estável, atender, por fim, aos desejos do pai e trabalhar em um escritório. Mas logo desiste e resolve definitivamente ir embora. Nesse momento, ocorre um dos diálogos mais comoventes da peça, o confronto final entre pai e filho. Ao saber que o filho iria embora de vez, Willy não se conteve e logo vociferou: "Eu quero que você saiba, no trem, nas montanhas, nos vales, onde você estiver, que você arruinou [abateu e limitou] a sua vida por causa da maldade [do ressentimento, do despeito, do ódio]!” (MILLER, 2009, p. $201)^{3}$. Magistral será a resposta de Biff:

\begin{abstract}
Eu nunca cheguei a lugar nenhum porque o senhor sempre me elogiou tanto que eu não consegui aceitar ordens de ninguém! É aí que está a culpa! (...) Eu não sou um líder, nem o senhor. O senhor nunca foi nada além de um trabalhador que acaba na lata do lixo como todo mundo! Eu valho um dólar por hora, Willy! Tentei em sete estados e nunca consegui mais do que isso. Um dólar por hora! Está me entendendo? Não vou mais trazer nenhum prêmio para casa e o senhor não vai mais esperar que eu traga! (MILLER, 2009, p. 261).
\end{abstract}

No auge da fúria, escreve Miller (2009), Biff ainda dirá: "Pai, eu não sou nada! Não sou nada, pai. O senhor não entende? Não tem ressentimento nenhum. Eu só sou o que sou, só

\footnotetext{
${ }^{3}$ Assim é apresentada a tradução portuguesa: "Eu quero que você saiba, no trem, nas montanhas, nos vales, onde você estiver, que você arruinou a sua vida por causa da maldade!” (MILLER, 2009, p. 259). Aqui a tradução não nos ajuda muito. Seria importante destacar, no texto original, as seguintes expressões: "I want you to know (...) that you cut down your life for spite". "Cut down": reduzir, cortar, diminuir, limitar, restringir, abater (algo/alguém); "For spite": despeito/ ódio, maldade, desprezo, rancor, ressentimento. "To spite": implicar, irritar (alguém), magoar, ofender, humilhar (alguém). Lembremo-nos do significado de "Biff": socar, golpear, soco, golpe, pancada, bofetada.
} 
isso.” (p. 202). Após ter dito isso, tendo esgotado a sua fúria, Biff cai em prantos, agarra seu pai, toca em seu rosto. Desconcertado, Willy se dá conta, naquele momento, que o filho o amava, que sempre o amou. Considerando isso, resolve se matar na crença de que a família poderia se beneficiar de seu seguro, especialmente, Biff, o filho no qual continuou a projetar todo o seu desejo de grandiosidade. Em seu enterro, vale destacar a fala de Charley, também irmão de Willy:

\begin{abstract}
Que ninguém acuse este homem. Vocês não entendem: Willy era um caixeiroviajante. E para um caixeiro-viajante a vida não tem chão firme. Ele não se prende a nada, não impõe a lei, nem dá remédio. Ele é um homem que vive no ar, montado num sorriso e num sapato engraxado. E quando começam a não sorrir de volta: é um terremoto. E quando o chapéu começa a ficar manchado, ele se acabou. Que ninguém acuse este homem. Um caixeiro-viajante tem de sonhar, rapaz. Faz parte dele (MILLER, 2009, p. 266-267).
\end{abstract}

Ora, se imaginássemos existir uma identificação entre o vendedor do filme de Farhadi e o viajante da peça de Miller, parece que conhecer os dramas do possível agressor de sua mulher não serviria de consolo à fúria de Emad. Nesse sentido, é importante considerar que toda a narrativa do filme de Farhadi segue, principalmente, a perspectiva de Emad sobre os fatos. Apesar de a violência ter ocorrido contra Rana, na sociedade na qual vivem os personagens do filme, de um modo mais intenso, todo e qualquer ato considerado como desonra realizado pela mulher ou contra ela é, consequentemente, ligado ao marido. A mulher é a sua extensão. Nessa perspectiva, é possível observar que, diante da desonra de uma mulher violentada, uma das punições possíveis será o apedrejamento, conforme prevê o Alcorão (1995). Que procedimento seria esse?

Segundo Aristóteles (2014), a lei do talião é definida pelos pitagóricos como uma forma de justiça que pressupõe que alguém possa sofrer do mesmo mal que tenha causado a outrem. Em razão disso, o seu fundamento seria uma concepção de justiça entendida como retaliação ${ }^{4}$. No entanto, embora a lei do talião seja preceituada quando se trata, por exemplo, de homicídio, o Alcorão dirá que, se o irmão do morto perdoar o assassino, haverá uma "mitigação e misericórdia" de Deus e, nesse caso, "quem vingar-se, depois disso, sofrerá um doloroso castigo" (ALCORÃO, 2a Surata, Al Bácara,178). Apesar de preceituar a vingança, fala-se também em tolerância. O que podemos deduzir disso? Parece-nos que o Deus mulçumano não deixa de ser também um Deus ambivalente. Pensando nessas questões,

\footnotetext{
${ }^{4}$ A lei mosaica, inclusive, segue essa orientação: "Se um homem desfigurar um compatriota, desfigurando-o, como ele fez assim se lhe fará: olho por olho, dente por dente. O dano que se causa a alguém, assim também se sofrerá (...)" (Levit. 24, 19-20). Essa ideia difere da concepção judaico-cristã de que a vingança só pertence a Deus. Dante, em sua literatura, fará disso o modelo moral do Inferno e do Purgatório.
} 
estaria Emad seguindo a lei do talião possivelmente tão presente no imaginário de sua cultura? O que pensar, todavia, de seu desejo desmedido de vingança, mesmo diante do pedido de perdão do possível agressor?

Se olhamos psicanaliticamente esses elementos da cultura, vendo neles uma configuração de nossas experiências emocionais, ou mesmo o entrelugar da relação que estabelecemos com o mundo, não podemos deixar de observar o quanto tanto o desejo de vingança como os sentimentos de humilhação, desonra, ultraje e vergonha estão tão profunda e intimamente vinculados. Essa vinculação nos revela, na verdade, que nos encontramos, sobretudo, em um registro narcísico. Igualmente podemos ver um certo sentido na acusação que Willy, no texto A morte de um caixeiro-viajante, faz contra Biff, considerando que ele havia arruinado a própria vida por puro despeito, por um ressentimento que abalou, como diria Kohut (1984), o seu "Self grandioso" ao perceber que a "imago parental idealizada" não passava de uma ilusão. $\mathrm{O}$ filho, portanto, reproduzia, de certo modo, a mesma experiência que seu pai fazia do mundo. Nesse sentido, a nosso ver, o mesmo se passa em $O$ Apartamento, de Farhadi: o que essas narrativas mobilizam em nós, dentre outros aspectos, é a percepção das consequências de um narcisismo não elaborado, as fissuras existentes entre o Self e seu ideal, fissuras essas potencialmente geradoras de uma desestabilizadora "fúria narcísica". Diante do ódio em perceber uma realidade distante do que se idealizou, a vingança surge como uma possibilidade de restauração de um equilíbrio que se sente abalado. Como entender isso? Vejamos a seguir.

\section{Os paradoxos da fúria narcísica: o Self grandioso e suas desventuras}

Em uma sociedade cujo imaginário se fundamenta, conforme Kohut (1984, p. 84-85), na "busca desenfreada, seja de objetivos grandiosos ou de fusão irrestrita com selfobjetos onipotentes", tirando disso a sua satisfação narcísica, elementos como honra, justiça, vergonha e humilhação ocupam um espaço privilegiado. Diante deles, a vingança - esse estado emocional que não encontra alívio enquanto o ódio de quem se sentiu ofendido não for aliviado - é a única possibilidade de expiação. Expiar, por conseguinte, os pecados cometidos contra um Self grandioso. Quando pensamos nos crimes cometidos contra esse Self, é importante salientar que está em jogo, de modo basilar, um processo de idealização. Ora, não nos teria ensinado Klein (1991, p. 89) que “a idealização é, portanto, um corolário da ansiedade persecutória e o seio ideal é a contrapartida do seio devorador"? Em outras 
palavras, como a própria Klein (1996, p. 392) irá nos explicitar, “a idealização é um processo fundamental na mente da criança pequena, pois ela ainda não consegue lidar de outra maneira com seus medos de perseguição (que são consequência de seu próprio ódio)”. Pensemos um pouco sobre essas questões.

Em sua linguagem metafórica, acreditamos que Klein (1996) está nos falando do modo como, primitivamente, lidamos com o nosso ódio, por sua vez, oriundo tanto da frustração como também das pulsões destrutivas que fazem parte de nosso psiquismo. Quando não há a possibilidade de pensar o ódio resultante da frustração, na relação com um determinado objeto, acabamos idealizando-o, por meio de um processo de cisão, como possibilidade de nos proteger do retorno desse mesmo ódio. Sentimo-nos perseguidos por esse sentimento e, para nos proteger, idealizamos o objeto como modo de neutralizarmos a sua possível vingança contra nossos fantasmáticos e inconscientes ataques. As relações que estabelecemos com esse objeto acaba se tornando parciais, ou seja, ou apenas o amamos, ou apenas o odiamos, uma vez que não conseguimos lidar com a ambivalência de encará-lo, ao mesmo tempo, como amável e odiável. É assim que consideramos que, nas relações entre Emad e a figura de um velho "degenerado" - acusação que ele também faz a Babak -, o que está em operação é o ódio, mas um ódio recíproco, o ódio que se imagina estar projetivamente presente em quem cometeu um ato de agressão e o ódio presente em quem se sentiu agredido. Como dirá o Alcorão, "se tiverdes de vos vingar, vingai-vos na medida em que fostes agredidos" (ALCORÃO, 16 a Surata, An Nahl, 126). Não se trata apenas de um mal realizado contra quem ele odeia por razões próprias, mas contra quem o ofendeu. Quais as consequências disso?

Mesmo estando em jogo aqui uma noção radical e ortodoxa de justiça, aquela que não se importa com suas consequências, para Emad, não basta que ela seja realizada. É preciso que o agressor seja humilhado e humilhado publicamente, que passe vergonha, a mesma vergonha que ele sente ter lhe sido infligida. Não é disso que já nos falava também o Talmude babilônico ao acentuar que "aquele que faz empalidecer o rosto de seu companheiro em público é como se tivesse derramado seu sangue"? (apud KOHUT, 1984). O rosto empalidecido de que nos fala o Talmude revela-nos um vermelho de vergonha, mas também um vermelho de ódio, de um ódio sem reparação; revela-nos, pois, a manifestação de uma "fúria narcísica", daí ser tão perigosa a agressão humana quando se liga a "constelações psicológicas" tão radicais como o Self grandioso e o objeto onipotente arcaico que, no adulto, encontra-se à serviço da inteligência. Emad é um exímio detetive. Nesse caso, a busca pela 
verdade é potencializada por uma capacidade de raciocinar que se encontra a serviço da "irracionalidade" de uma "atividade vingativa". O que isso nos diz da "fúria narcísica"? Como salienta Kohut (1984, p. 99),

\begin{abstract}
A necessidade de vingar-se, de reparar uma afronta, de desfazer uma ofensa a qualquer custo, e a compulsão inexorável, profundamente enraizada, de perseguir todos esses objetivos e que não dá sossego àqueles que sofreram uma ferida narcísica - esses são os aspectos característicos da fúria narcísica em todas as suas formas e que a distinguem das outras espécies de agressão.
\end{abstract}

Se pensamos no mito grego que serve de nome à compreensão psicanalítica de narcisismo, podemos considerar esse conceito, em linhas gerais, como o amor que alguém pode dirigir para si mesmo, tal como Narciso fascinado por sua própria imagem. Isso é o que fazia com que, inicialmente, o termo indicasse uma perversão, ou seja, o comportamento controverso de alguém que decidira tomar o próprio corpo como um objeto amoroso. Freud, como diz Garcia-Roza (1995, p. 42), dá um novo significado ao conceito de narcisismo, dado que ele passa a ser “(...) condição de formação do eu, chegando mesmo a se confundir com o próprio eu".

A compreensão freudiana de narcisismo, todavia, encontra-se ligada à sua teoria das pulsões, o que possibilita falar em um narcisismo primário - quando a libido encontra-se investida no próprio eu antes de se transformar em uma libido objetal - e em um narcisismo secundário - quando, por alguma razão, após ter se dirigido a algum objeto, a libido retorna para o eu, entendido como um reservatório permanente a partir do qual se são todos os investimentos objetais. Mas, lembra Garcia-Roza (1995, p. 46), “(...) a distinção de narcisismo primário e narcisismo secundário não adquire contornos bem definidos senão a partir da segunda tópica freudiana". O que nos importa aqui, mais do que aprofundar um conceito metapsicológico, é a compreensão do narcisismo como um componente fundamental na constituição de uma subjetividade e que se dá na relação que, inicialmente, ela estabelece com seus primeiros cuidadores. Falar em narcisismo significa falar, em síntese, do modo como, primitivamente, constituímos a imagem que temos de nós mesmos, tal como nos esclarece, ressalvadas as devidas diferenças, a metáfora lacaniana da "fase do espelho". Falar de falhas ou de feridas narcísicas significa assinalar que algum problema importante ocorrera nos processos de narcisização do Self. É assim que Kohut irá pensar as relações entre "Self grandioso" e "imago parental idealizada". Que contribuições essas ideias trazem à concepção freudiana de narcisismo? 
Para Kohut (1988), esses dois conceitos constituem as tentativas realizadas pela criança em recuperar um estado que ela considera ser de plenitude. É importante que, inicialmente, haja um sentimento de perfeição e, como defesa, tudo o que é tido como imperfeito seja visto como estando exclusivamente fora do Self. Quando essas tendências são acolhidas pelos cuidadores e respondidas de modo empático e suficiente, a criança abandona suas necessidades de grandiosidade e consegue assumir um modo de funcionamento mais realista. À medida que a criança vai internalizando a experiência emocional vivenciada com esses cuidadores, eles vão se constituindo para ela, conforme a linguagem da psicanálise clássica, como "objetos internos", ou seja, a presença do outro no interior do próprio eu, poderíamos dizer, em sua vida imaginária. Kohut, em sua linguagem, chamará esses objetos ou objetos internos de selfobjetos. Falhas na experiência com esses selfobjetos, por conseguinte, tornamse falhas na própria constituição narcísica do Self. Pensando assim, a fúria narcísica poderia ser considerada, em suma, como um resultado dessa falha.

Kohut situa a fúria narcísica como um fenômeno específico no vasto campo psicológico da destrutividade humana, no qual também poderíamos encontrar a agressão e a raiva. Essa fúria funcionaria, pois, como a resposta de um sujeito que, em razão de sua história - muitas vezes, tratado sadicamente por seus cuidadores na infância -, encontra-se "narcisicamente vulnerável", mas de uma vulnerabilidade à flor da pele. É assim que compreendemos como Emad decidira tão prontamente lutar e, nessa luta, identifica-se com seu agressor, responde à humilhação com sadismo. O direito que lhe serve de referência é um “direito masculino". Em alguns momentos, esquece-se da própria dor vivida por Rana. Transfere seu ódio aos seus alunos, com os quais, no início do filme, tinha uma relação muito amistosa. Para quem sofre, o trauma é evidente, é a invasão de um corpo estranho em sua mente, de um ataque à sua própria potencialidade e liberdade de ser e de existir. Para quem inflige um trauma, a violência alcança um campo antropológico e metafísico. O que essa afirmação nos revela?

Por um lado, encontramos o reconhecimento da própria agressividade, até então oculta, como parecem sugerir os olhares de Emad e de Rana no final do filme. Como viver depois de abalado o edifício da relação que os unia e que parecia ser tão sólido? Por outro lado, deparamo-nos com a descoberta de que essa mesma agressividade existe como possibilidade do existir humano, não mais como um ser idealizado, pronto, senhor de si, mas como uma construção, portanto, também passível de desconstrução, de demolição, de se encontrar em meio a ruínas. Nessa conjuntura, o opositor de Emad não é vivido como distinto dele, não é aquele que atrapalha a realização de seus desejos narcísicos integrados à realidade. Pelo 
contrário, é aquele que é experimentado como expressão de uma "falha numa realidade narcisicamente percebida", ou seja, "o inimigo é parte recalcitrante do próprio self expandido sobre o qual a pessoa narcisicamente vulnerável contava exercer pleno controle" (KOHUT, 1984, p. 106).

Nisto consideramos estar, pois, um dos paradoxos desse "narcisismo extremamente vulnerável", ou antes, da "fúria narcísica". Mas, aqui encontramos também a proximidade entre Emad e Biff. Biff precisa da aprovação do pai para ir embora, para poder ser ele mesmo, perde o seu desejo de crescimento diante da desilusão, ao perceber que o pai não é perfeito. Emad não tolera a figura da desonra, não supera o seu ressentimento, o seu despeito, mas os converte em agressão. $\mathrm{O}$ vendedor do filme é passivo, um velho doente, pede perdão; o vendedor de Arthur Miller chama o filho de um "cachorro vingativo e mau" (MILLER, 2009, p. 262). Emad é o personagem que ocupa esse espaço da vingança, ele habita a fronteira entre o ressentimento e a revolta. Sua fúria narcísica acaba cegando-o. Nos Estudos sobre a histeria, Freud (2006) já salientava que "a reação da pessoa insultada em relação ao trauma só exerce um efeito inteiramente 'catártico' se for uma reação adequada - como por exemplo, a vingança" (p. 44). No entanto, ele percebia haver um outro caminho frente a essa situação. Dizia também que “(...) a linguagem serve de substituta para a ação; com sua ajuda, um afeto pode ser 'ab-reagido' quase com a mesma eficácia (FREUD, 2006, p. 44). O que isso nos diz? Para Emad, faltou a palavra. Ele vive como se houvesse apenas a possibilidade de concretização de um "ódio assassino" ou de uma passividade que cultiva a lembrança da desonra como a máscara mortuária do sonho e da criação. É assim que parecia encarar o silêncio de Rana. Ele prefere assumir a atitude da criança brincando com o carretel, de quem nos fala Freud em Além do princípio do prazer, cuja satisfação estaria na fantasia de que possuiria um controle sobre as idas e vindas da mãe, a técnica de um jogo simbólico no qual a dor e o desconforto tanto de uma ferida narcísica como da angústia do desamparo pareciam desaparecer na passagem de uma atitude passiva para uma atitude ativa (FREUD, 1996, p. 2427). Assim é a vingança de Emad: de humilhado e ferido, assume a figura do opressor e, nesse papel, busca o gozo da reafirmação de uma superioridade fantasiada. A qualquer custo, ele precisa da cura da chaga que o sentimento de humilhação lhe abriu.

O problema de Emad é a impossibilidade de permitir que a ofensa se torne uma "coisa pretérita”. Dela ele faz o seu ofício. Em seu desespero em reparar a sua honra, faz aquilo que Nietzsche (2009) havia já denunciado, sacraliza “(...) a vingança sob o nome de justiça como se no fundo justiça fosse apenas uma evolução do sentimento de estar-ferido" (p. 62). 
Não se percebe aquela agressividade a serviço da vida, talvez a mesma que vemos nas reações de uma presa diante de seu predador, quando a resposta é uma resposta pela vida, é um protesto que revela o desejo de viver e não de matar. Daí o que consideramos ser, pensando nas relações entre o desejo de vida e de morte, o segundo paradoxo presente na fúria narcísica encenada por esses personagens, o suicídio de Will e a sede de justiça de Emad: o outro é um presente-ausente, não há possibilidade de percebê-lo em suas complexidades e ambivalências, não há espaço para o diálogo. Se quiséssemos encontrar uma tradução poética para essa experiência expressa nesse drama, parece-nos que o enigmático poema de Baudelaire (2015, p. 249; 251), intitulado "O tonel do ódio", na tradução de Ivan Junqueira, poderia funcionar como uma boa referência:

\begin{abstract}
O Ódio é o tonel das pálidas Danaides frias;/ Por mais que da Vingança o braço rubro e forte/ Derrame-lhe às entranhas ermas e sombrias/ Baldes cheios de sangue e lágrimas da morte,// O Diabo lhe abre furos nunca imaginados,/ Que verteriam séculos de esforço e suor,/ Mesmo que à vida ela trouxesse os condenados/ Para o corpo infligir-lhes castigo maior.// O Ódio é um ébrio perdido ao fundo da taverna,/ Que sente sua sede emergir do licor/ E ali multiplicar-se qual hidra de Lerna.// Mas quem bebe feliz verá seu vencedor,/ $\mathrm{E}$ ao ódio resta apenas a amarga certeza/ De saber que jamais dormirá sob a mesa.
\end{abstract}

Na mitologia grega, as Danaides foram condenadas a uma tarefa impossível, a encher um tonel que, contudo, não possuía fundo. Da mesma forma, encontramos a tarefa "quase" impossível, realizável apenas mediante o seguinte trabalho hercúleo: vencer a hidra de Lerna, um monstro de corpo de dragão e várias cabeças de serpente. A cada cabeça que lhe era cortada, conforme algumas versões do mito, nasciam duas em seu lugar. O poeta nos fala de um ódio e de uma vingança devoradores, impossíveis de serem reparados e, mais do que isso, sem a possibilidade de um "sono embebedado", "de dormir sob a mesa". Quanto a esse sono, é interessante como muitas pessoas, frente à insônia, recorrem ao álcool como uma tentativa de anestesiar uma dor inominável, de se desligarem de um sofrimento psíquico atormentador. Podemos dizer que, para outras pessoas, o ódio pode servir também como uma tentativa de embebedar a dor, porém, igualmente ineficaz, se considerarmos ser o "sono embebedado" pelo álcool também um sono não "reparador", outrossim, incapaz de "reparar a dor" psíquica. O que essa imagem nos fala da agressividade e das feridas narcísicas que encontramos nos dramas descritos tanto na peça como no filme sobre os quais estamos refletindo?

Se pensamos na teoria kleiniana, encontramos a ideia de que experiências muito precoces de uma frustração muito intensa podem favorecer a fantasia de um objeto interno e externo tanto maus quanto perseguidores. É assim que a ausência da mãe pode ser vivida, na 
fantasia, pelo bebê. Porém, como lembra Kernberg (2006) em seu estudo sobre a destrutividade, em um processo superior do desenvolvimento, já não haveria o desejo de destruir esse mau objeto, mas, a partir de uma associação entre dor e prazer, fazê-lo sofrer, dominá-lo e controlá-lo do modo mais sádico possível. O ódio se torna tão intenso que é capaz de destruir a própria percepção que se pode ter dele. Nesse processo, a culpa pode se tornar um fantasma inexpugnável e o sentimento de vazio, desesperadamente, um tonel sem fundo e uma sede insaciável. Nessa perspectiva, ainda pensando por imagens poéticas, se é válida a constatação de André Gide (1984, p. 11) de que "Narciso sonha no paraíso", o paraíso de Biff e de Emad, diferente daquele almejado pelo poeta - constituído por uma rede de símbolos -, é, não só sem possibilidade de simbolização, mas, fundamentalmente, dantesco.

\section{Considerações finais}

O filme $O$ Apartamento pode despertar em nós ideias de traumas, de ressentimentos e de vingança, ou seja, mobiliza-nos a pensar em nossas angústias. Apresenta-nos mais perguntas do que respostas. Ao final, parece querer despertar, em seu espectador, o que, no início do filme, com a imagem de um prédio em ruínas, parecia ser apenas uma cena com efeitos especiais. Ao acompanhar seus dramas, fica difícil saber o que é justiça e o que é verdade. É a nossa própria compreensão de moral que fica abalada e, mais do que isso, encontramo-nos desmascarados em nosso ressentimento e em nossa fragilidade. É tanto um modelo de humanidade que acreditava ser senhora absoluta de si e de suas razões, como a experiência de um "narcisismo extremamente vulnerável", em seu contínuo embate com seus desejos de vida e de morte, que, por fim, revela-se estar em um processo contínuo e dramático de construção e de desconstrução. Por sua vez, esse narcisismo, quando não elaborado, levanos às desventuras da repetição, ao "além" do princípio de prazer. Como encontrar saídas nesse labirinto? Melanie Klein (1996, p. 392) parece nos apontar um caminho a ser pensado:

Só quando as ansiedades arcaicas são aliviadas através de experiências que aumentam o amor e a confiança é que se torna possível estabelecer o processo essencial de juntar os vários aspectos dos objetos (externos e internos, "bons" e "maus", amados e odiados). Só então o ódio é realmente mitigado pelo amor - o que significa uma redução da ambivalência. Enquanto a separação entre esses aspectos contrastantes (...) mantém-se com toda sua força, os sentimentos de amor e ódio permanecem de tal forma separados, que o amor não consegue mitigar o ódio. 
Como dizia o irmão de Willy, Charley, o problema do caixeiro-viajante era que, apesar de ser um vendedor, esquecia-se de que, mais importante do que ser visto e admirado por todos, a riqueza de uma pessoa estava em ter coisas que poderiam ser vendidas. Ora, não era justamente contra isso que Willy construiu seu mundo de delírios? Não estaria a dor e o "ódio assassino" de Emad ligados ao abalo e à frustração de um desejo de ser visto e admirado tal como uma criança se vê refletida nos olhares de uma mãe amorosa? Seriam simplesmente os movimentos de agressão, apresentados nessas narrativas, um impulso biológico ou culturalmente aprendido? Onde estaria o valor de uma ofensa? Aqui nos limitamos a pensar na hipótese de uma "fúria narcísica", derivada possivelmente de uma experiência precoce muito traumática e repetida ao longo da vida. A esse respeito, pensando na teoria do endereçamento, entendemos ser essa uma compreensão possível mobilizada no imaginário de quem se encontra familiarizado com o discurso psicanalítico. Pensando nessa experiência traumática, como sobreviver a uma ferida tão profunda?

Se considerarmos as palavras de Klein (1996), todas e quaisquer experiências que contribuem para o aumento do amor e da confiança podem colaborar para a elaboração dessa ferida, desde que a pulsão de morte não seja muito excessiva, pois é preciso considerar também o que há de constitucional em cada um de nós. Na reconciliação entre Biff e Willy, é possível perceber esse processo. Biff parece ter conseguido integrar a imagem do pai, não mais vivida como um objeto arcaico onipotente. Assim ele se tornou mais realista e assumiu a ambivalência de um pai que não é perfeito. Em uma linguagem kleiniana, poderíamos identificar um movimento de oscilação para uma posição depressiva, o que não ocorrera com Willy que permanecera preso em defesas excessivamente esquizoparanoides. Pensando em Kohut, Willy não conseguiu abandonar as defesas, aparentemente eficazes, de um Self grandioso. O mesmo acontecera com Emad, preso em um ódio que nos leva a pensar ser, em nossa imaginação, uma resposta à frustração arcaica de sua necessidade de amor. Pouco sabemos da história de Emad, temos apenas o drama de um adulto, porém, repleto de traços de conflitos próprios de um Self emocionalmente infantil. Daí o recurso à ideia kohutiana de um "narcisismo vulnerável" ou, conforme acrescentamos e preferimos destacar, de um narcisismo "extremamente" vulnerável, "à flor da pele".

$\mathrm{Na}$ lida com essa vulnerabilidade, chamou a nossa atenção a ausência de um amor capaz de mitigar o ódio, o que ocorrera tanto no filme como na peça, se considerarmos o fato de que ambos terminam com a morte do vendedor, sendo que, no filme, deparamo-nos com o triunfo de um ódio maníaco e, na peça, de um delírio megalomaníaco. Não caberia aqui tratarmos das 
possibilidades kohutianas de uma restauração do Self, o que demandaria, diferente da nossa proposta, a discussão clínica dos processos transferenciais que ocorrem no contexto de um setting psicanalítico. Desse modo, não distante do pensamento kohutiano, ocorrera a nossa aproximação da proposta kleiniana de um ódio mitigado pelo amor. Porém, cabe lembrarmonos de que, conforme a ressalva de Klein, essa mitigação se dá tão somente quando nos tornamos capazes de lidar com a ambivalência e seus paradoxos. Sobre a vivência do paradoxo, embora tenhamos optado apenas em reconhecê-lo nessas narrativas, vale dizer que o entendemos tal como Racamier (1978, p. 947), a saber, uma “(...) formação psíquica que faz com que duas proposições, ou injunções, inconciliáveis e, no entanto, não opostas, liguem-se entre si e remetam-se reciprocamente". O que acaba ficando subentendido, em um paradoxo, é a identidade entre elementos contrários, o que gera uma situação insolúvel, a constituição de um impasse, ao menos enquanto a confusão não for desfeita. Porém, o que nos interessou aqui foi observar como o paradoxo está presente, muitas vezes, na experiência afetiva que fazemos do mundo, sem adentrar em seu significado clínico, diferentemente do que fizera o próprio Racamier. Por isso, essa definição se tornara importante apenas em nossas considerações finais, após vermos como injunções inconciliáveis e não opostas podem compor a nossa experiência tanto de alguns aspectos das obras que investigamos como de nossos processos de narcisização e, consequentemente, de suas falhas. É assim que, por um lado, o paradoxo se faz presente na articulação entre os traços de endereçamento do filme e a resposta do espectador, o que nos leva a um entrelugar volátil, cheio de fissuras e habitado pelo estranhamento; por outro lado, esse paradoxo se articula também entre o que poderia ser dito pelo filme e o que foi, de fato, dito. Os modos de organização das fronteiras entre o dito e não dito serão, por sua vez, o que permitirá uma construção eficaz de sentidos, capaz de gerar processos de identificação e de mobilização emocional.

Por fim, pudemos percorrer algumas trilhas, possibilitadas pela experiência do filme e dos efeitos de sua intertextualidade, da relação entre os personagens da narrativa cinematográfica e da peça de Miller, das injunções inconciliáveis e não opostas de nossas feridas narcísicas, seja o inimigo odiado como parte constitutiva e não reconhecida do próprio Self, seja, na ausência de um registro psíquico da alteridade e da diferença, a não percepção do outro em sua inteireza, complexidades e ambivalência. $\mathrm{O}$ caixeiro-viajante que adentra o apartamento, tal qual um sentimento de inquietante estranheza (Unheimlich) que invade, traumaticamente, o nosso psiquismo, é um ser de fissura que nos revela aquilo que a vulnerável grandiosidade de nosso Self deseja não apenas não reconhecer, mas também 
violentamente expulsar. Que revelação seria essa? Pensando em tudo o que refletimos neste artigo, à guisa de conclusão, ao menos provisoriamente, talvez seja a ideia de que, e nisto há também um paradoxo, uma identidade plena, com todas as grandiosas virtudes desejadas, no final das contas, não passa de um mito, não tão diferente daquele do paraíso perdido que tanto faz inquietar o nosso coração.

\section{Referências}

ALCORÃO. Rio de Janeiro: Associação Cultural Internacional Gibran, 1995.

ARISTÓTELES. Ética a Nicômaco. São Paulo: EDIPRO, 2014.

BAUDELAIRE, C. As flores do mal. Rio de Janeiro: Nova Fronteira, 2015

BION, W. R. Estudos psicanalíticos revisados. Rio de Janeiro: Imago, 1994.

BREUER, J.; FREUD, S. Estudos sobre a histeria. In: FREUD, S. Edição standard brasileira das obras psicológicas completas de Sigmund Freud. v. 2. Rio de Janeiro: Imago, 2006.

ELLSWORTH, E. Modos de endereçamento: uma coisa de cinema; uma coisa de educação também. In: SILVA, T. T. da. (org.). Nunca fomos humanos: nos rastros do sujeito. Belo Horizonte: Autêntica, 2001.

FREUD, S. Além do Princípio de Prazer. In: FREUD, S. Edição standard brasileira das obras psicológicas completas de Sigmund Freud. v. 18. Rio de Janeiro: Imago, 1996.

FREUD, S. 21 de setembro de 1897. In: MASSON, J. M. (Ed.). A correspondência completa de Sigmund Freud para Wilhelm Fliess - 1887-1904. Rio de Janeiro: Imago, 1986.

GARCIA-ROZA, L. A. Artigos de metapsicologia (1914-1917): narcisismo, pulsão, recalque, inconsciente: Rio de Janeiro: Zahar, 1995.

GIDE, A. O Tratado de Narciso (Teoria do símbolo). São Paulo: Flumen, 1984.

KERNBERG, O. Aggressivity, Narcissism, and Self-Destructiveness in the Psychotherapeutic Relationship. New Developments in the Psychopathology and Psychotherapy of Severe Personality Disorders. New Haven: Yale University Press, 2004.

KLEIN, M. Inveja e Gratidão e outros trabalhos (1946-1963). Rio de Janeiro: Imago, 1991.

KLEIN, M. Amor, culpa e reparação e outros trabalhos (1921-1945). Rio de Janeiro: Imago, 1996.

KOHUT, H. Análise do self: uma abordagem do tratamento psicanalítico dos distúrbios narcísicos de personalidade. Rio de Janeiro: Imago, 1988.

KOHUT, H. Self e Narcisismo. Rio de Janeiro: Zahar, 1984.

MERLEAU-PONTY, M. Sens et non-sens. Paris: Gallimard, 1996. 
MILLER, A. A morte de um caixeiro-viajante e outras 4 peças. São Paulo: Companhia das Letras, 2009.

MILLER, A. Muerte de un viajante. Barcelona: Tusquets, 2015.

O APARTAMENTO. Direção: Asghar Farhadi, Produção: Asghar Farhadi e Alexandre Mallet-Guy. Paris/Irã: Memento Films Production/ Arte France Cinéma, 2017.

NIETZSCHE, F. Genealogia da moral: uma polêmica. Trad. De P. C. de Souza. São Paulo: Companhia das Letras, 2009.

RACAMIER, P.-C. Les paradoxes des schizophrènes. Revue Française de Pschanalyse, Paris, v. 42, p. 877-969, setembro/dezembro, 1978.

SILVA, T. T. da. (org.). Nunca fomos humanos: nos rastros do sujeito. Belo Horizonte: Autêntica, 2001.

Recebido em 06/07/2018 Aceito para publicação em 31/07/2018 